\title{
Marital distress and disease progression: A systematic review*
}

\author{
Ming Guan ${ }^{1,2 \#}$, Bingxue $\operatorname{Han}^{2}$ \\ ${ }^{1}$ Henan University, Kaifeng, China; ${ }^{\#}$ Corresponding Author: gming0604@sohu.com, gming0604@163.com \\ ${ }^{2}$ Xuchang Univercity, Xuchang, China
}

Received 28 January 2013; revised 1 March 2013; accepted 1 April 2013

Copyright (C) 2013 Ming Guan, Bingxue Han. This is an open access article distributed under the Creative Commons Attribution License, which permits unrestricted use, distribution, and reproduction in any medium, provided the original work is properly cited.

\begin{abstract}
Objective: To review the state of research on the association between marital distress and disease progression. Methods: The PubMed Central, Wiley Interscience, Sciencedirect, Biomed central and Springer-link were searched to identify studies published between January 1984 and October 2012 on disease progression. Articles meeting the following criteria were selected for review: 1) study subjects were spouses, 2) the article was published within the past 28 years in a peer-reviewed journal, and 3) the research included at least one of the following outcomes-marital distress or disease progression. Articles were different on time span, the number of surveys, and the definition of disease. Results: Out of 72 screened articles, 18 met our criteria. Research demonstrates that marital distress and disease progression appear to have bidirectional influence on each other. Conclusion: Marital distress has a significant effect on disease progression. This article summarizes what is known about the association of marital distress on disease progression among spouses with disease. The authors speculate that associations between marital distress and disease progression will motivate policy makers in developing countries to allocate more resources towards spousal service.
\end{abstract}

Keywords: Marital Distress; Disease Progression; Relationship

*One of the authors MG was co-author on one of the reviewed articles. However, the review was performed by two of the authors, and there were no discrepancies between these two on the findings from that article. The authors declare that they have no competing interests.

\section{INTRODUCTION}

Marriage appears to buffer reports of both practical and psychosocial problems, and leads to less awareness and use of services. Marital distress should be considered as a source of dysfunctional behavior in marital interactions involving depressed individuals [1]. It indicated that marital distress associated with recalling a marital conflict was manifest in elevated blood pressure and heart rate, particularly among women characterized as experiencing high levels of distress in their marriage [2]. A study in Singapore [3] showed that marital distress was a significant predictor of depressive symptoms, health, and work satisfaction. Mead (2002) showed gender contributes to marital distress and depression but does not appear to be the cause of either [4]. Marital distress and depression appear to have bidirectional influence on each other. The depressed spouse's depression has a marked impact on the marital adjustment of the nondepressed spouse. Both marital distress and depression appear to be chronic.

Research showed that marital distress was a significant predictor of depressive symptoms, health, and work satisfaction [3]. To my knowledge, the study of effects of marital distress on disease progression can be traced back to 1984, marital distress in spouses of chronic low back pain patients [5]. This area of study is important because although there have been a few studies addressing the relationship between disease progression and marital distress and the effects of marital distress on disease progression. This area of work is also very important because improved understanding of factors that may either contribute to or prevent against marital distress can provide insight for developing interventions that might enhance the effectiveness of preventing or minimizing disease progression.

Questions that need to be asked include the followings:

- Can marital distress influence disease progression? 
- Can marital distress be prevented efficiently?

- Should spouses with disease be eager to do everything they can to promote their health?

To our knowledge, no previous systematic literature reviews on associations between marital distress and disease progression exist. However, it is necessary for researchers in the field of family therapy to find the review. Our objective was to conduct a systematic critical literature review to improve our understanding of the association of marital distress on disease progression among spouses with disease.

\section{METHOD}

\subsection{Search Strategy}

A systematic literature search was conducted in PubMed Central, Wiley Interscience, Sciencedirect, Biomed central,Springer-link and included studies published between January 1984 and October 2012. Search terms included both marital distress and disease. Articles published before 1984 are not included as earlier findings may be less relevant to more recent marital distress and its effect, due to changes in disease progression.

\subsection{Screening of Articles}

In order to select a final set of articles for review, we examined the title and abstract of the articles and included articles if: 1) they were relevant to at least one of the disease, 2) year was included, and 3) if the articles dealt with population (one or both of spousal populations with disease). A search for articles was performed (until October 2012) using the search terms: "marital distress"; "disease progression". An additional citation search was performed of reference lists of the retrieved articles. We restricted with English-language publication. The Review question is: does marital distress influence disease progression or how does disease progression influence marital distress?

The reference lists of potentially relevant articles were examined for additional references and the "related" search key was used from highly relevant articles to search for additional publications. We limited our automated searches to articles in English. To identify a comprehensive set of possible search terms of marital distress and disease progression, we consulted indexed terms in titles of published journal articles in this area. We searched eligible citations using disease progression and marital distress. Searches were modified for Embase and Google Scholar databases to conform to their search structures.

\subsection{Exclusion}

Selection of articles were made by MG and verified by $\mathrm{BXH}$ according to predetermined criteria for inclusion and exclusion that were defined by $\mathrm{MG}$ in relation to the objectives of the review. Exclusion criteria were: 1) Not published as a full article (conference proceedings excluded); 2) Population not disease; or 3 ) Not a study. Two reviewers (MG and $\mathrm{BXH}$ ) independently reviewed the titles and abstracts of citations generated by the search to assess their eligibility for further review based on the selection criteria, and chose relevant articles for possible inclusion.

\section{RESULTS}

\subsection{Search Results}

From 72 articles found through the search strategy (Box 1), 9 were from Springer-link, 17 from Biomed central, 28 were from Wiley Interscience, 14 from Sciencedirect, and 4 from PubMed Central. After the selection process (Box 1), we identified 18 articles for this review.

\subsection{Study Characteristics}

The included articles were published in 39 different journals of which 2 articles (Family Process), 4 articles (Journal of Marital and Family Therapy), 3 articles (Cancer), 2 articles (J Abnorm Psychol.), 2 articles (J Consult Clin Psychol.), other articles from Behavior Therapy, Behaviour Research and Therapy, Behav Modif., Behav Med., J Pers Disord., Advances in Behaviour Research and Therapy, J Fam Psychol., J Pers Assess., Family Relations, PAIN, Clinical Psychology Review, Journal of Clinical Psychology in Medical Settings, Clinical Psychology \& Psychotherapy, The Breast Journal, Psychosom Med., Psycho-Oncology, Journal of the European Academy of Dermatology and Venereology, Journal of Anxiety Disorders, Addiction. There was an uneven distribution of publications between 2000 and 2011, but

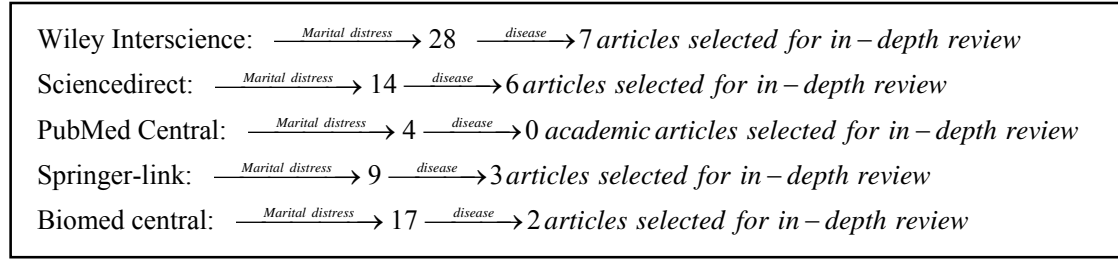

Box 1. Screening process. 
with no clear patterns across the decade. Studies had diverse study designs and populations. 10 articles examined the link between marital distress and disease progression, and all demonstrated significant and discouraging associations. See Table 1.

Except the above studies, other results intensified the relationship. There has been interest in recent years in the relationship between marital distress and psychopathology. Satin et al. indicating that depression is predictive of all-cause mortality, but not disease progression, in cancer patients [16]. Divorce and destructive couple conflict are major risk factors for many forms of dysfunction and psychopathology in the family. Couple relationship education has been offered in an attempt to reduce those risks and enhance couple outcomes [17]. There are several factors that contribute to marital distress. Gender contributes to marital distress but does not appear to be the cause of it. Marital distress and depression appear to have bidirectional influence on each other. The depressed spouse's depression has a marked impact on the marital adjustment of the nondepressed spouse. Both marital distress and depression appear to be chronic [4]. Husband-wife discrepancies with respect to who does have the various role assignments were found to be higher in the marital therapy couples [18]. The effect of intracouple coping concordance on psychological and marital distress was examined in a sample of 46 couples undergoing different stages of infertility treatment. Results indicate that the effect of coping similarity within couples is dependent on both the type of coping examined and the stage of the stressor. Specifically, for women the use of high levels of task-oriented coping by their partners and themselves is associated with the highest level of marital satisfaction. The findings also indicate that the use of high emotion-oriented coping by both partners is associated with the most psychological distress for men [19]. It was found that marital distress is associated with greater mental health care service utilization suggests that clinicians should assess both individual and relationship factors among individuals presenting for treatment [20].

\section{DISCUSSION}

The purpose of this review was to gain an understanding of association of marital distress on disease progression among spouses with disease. In particular, it would have been more informative if researchers could have reported marital distress on disease progression among spouses with disease at the various surveys and at-

Table 1. List of review articles by Disease type, Research method, and relations outcome measured.

\begin{tabular}{|c|c|c|}
\hline References & Disease type & Results \\
\hline$[6]$ & $\begin{array}{l}\text { advanced } \\
\text { prostate cancer }\end{array}$ & $\begin{array}{l}\text { It revealed strong relations between physical and mental health with marital satisfaction for both survivor } \\
\text { and caregiver. caregiver physical and mental health was related with the survivor's marital satisfaction. }\end{array}$ \\
\hline [7] & vitiligo & $\begin{array}{l}\text { Patients with vitiligo experienced significantly impaired health-related quality of life and unstable marital } \\
\text { relationships. }\end{array}$ \\
\hline [8] & PTSD symptom & $\begin{array}{l}\text { Spouses' perceptions of veterans' symptom severity were positively associated with spouses' psycho- } \\
\text { logical and marital distress; spouses' perceptions fully mediated the effects of veterans' self-reported } \\
\text { PTSD severity on spouses' distress. }\end{array}$ \\
\hline$[10]$ & Breast Cancer & $\begin{array}{l}\text { Marital distress is not only associated with worse psychological outcomes for breast cancer survivors, but } \\
\text { poorer health and a steeper decline in physical activity. These novel data show recovery trajectories for } \\
\text { breast cancer survivors to be constrained for those also coping with ongoing difficulties in their marriage. }\end{array}$ \\
\hline [11] & $\begin{array}{l}\text { breast } \\
\text { cancer }\end{array}$ & $\begin{array}{l}\text { Being single was associated with increasing depression symptoms over time in both navigators and so- } \\
\text { journers compared with being married. By } 12 \text { months, these increases crossed above the clinical cut-off } \\
\text { for significant depression symptoms. being single predicted a significant increase in navigators' } \\
\text { re-experiencing of trauma symptoms. Over time, married sojourners increased significantly in emotional } \\
\text { well-being. }\end{array}$ \\
\hline$[12]$ & $\begin{array}{l}\text { DSM-IV } \\
\text { psychiatric } \\
\text { disorders }\end{array}$ & $\begin{array}{l}\text { Marital distress was associated with (a) broad-band classifications of anxiety, mood, and substance use } \\
\text { disorders and (b) all narrow-band classifications of specific disorders except for panic disorder, with the } \\
\text { strongest associations obtained between marital distress and bipolar disorder, alcohol use disorders, and } \\
\text { generalized anxiety disorder. The association between marital distress and major depressive disorder } \\
\text { increased in magnitude with increasing age. }\end{array}$ \\
\hline$[13]$ & $\begin{array}{l}\text { borderline } \\
\text { personality } \\
\text { disorder }(\mathrm{BPD}) \\
\text { symptoms }\end{array}$ & $\begin{array}{l}\text { BPD symptom severity was positively associated with marital distress. Associations remained significant } \\
\text { when controlling for presence of } 12 \text {-month Axis I disorders. }\end{array}$ \\
\hline [14] & $\begin{array}{l}\text { metabolic } \\
\text { syndrome } \\
\text { (MetS) }\end{array}$ & $\begin{array}{l}\text { For women, greater marital distress was significantly associated with increasing likelihood of meeting } \\
\text { criteria for the MetS and with the individual MetS criteria of elevated blood pressure and elevated fasting } \\
\text { glucose. marital distress was not significantly associated with the MetS or any of the individual MetS } \\
\text { criteria for men. }\end{array}$ \\
\hline$[15]$ & $\begin{array}{l}\text { Obsessive } \\
\text { Compulsive } \\
\text { Disorder }\end{array}$ & The level of marital distress was related to the severity of disease. \\
\hline
\end{tabular}


tempted to take into account the possible effect of marital distress. Kung (2000) suggested elements of marital therapy that are conducive to effective treatment outcome [21]. It is recommended that treatment be designed to help couples be supportive of each another, to adapt, and to cope with the depressive symptoms within the framework of their ongoing marital relations [4]. These results suggest that the physiological concomitants of stress and emotional upset associated with marital distress are manifest in elevated blood pressure that is most pronounced in the home environment [22]. It suggested elements of marital therapy that are conducive to effective treatment outcome [21].

Couples therapy is an important element of effective treatment of depression, alcohol abuse, anxiety disorders, and the functional psychoses [23]. Before therapy of marital therapy, some methods can be used to examine marital distress, such as Minnesota Multiphasic Personality Inventory-2, Dyadic Adjustment Scale, Psychopathic Deviate clinical scale and Family Problems content scale [24]. In the last decade, two approaches have emerged as the most promising because they are supported by some controlled outcome studies: Behavioral Marital Therapy (BMT) and Communication Training (CT). Results of both methods showed substantial improvement after therapy when compared to the waiting-list control group whereas couples in CTCG improved on only 1 out of 7 comparisons. When considering the long-term effectiveness, BMT seems to be moderately more effective in stabilizing change than a CTformat [25]. A study has evaluated the efficacy, effectiveness, and clinical significance of empirically supported couple and family interventions for treating marital distress and individual adult disorders, including anxiety disorders, depression, sexual dysfunctions, alcoholism and problem drinking, and schizophrenia. In addition to consideration of different theoretical approaches to treating these disorders, different ways of including a partner or family in treatment are highlighted: partner-familyassisted interventions, disorder-specific partner-family interventions, and more general couple-family therapy [26]. The marital distress prevention program for couples is able to improve psychological well-being among both genders and life satisfaction among women. It seems that these effects are stable over 1 year. On the other hand, no significant effects could be observed on physical wellbeing [27].

Research [28] suggests the possibilities for preventing marital distress through teaching couples to improve communication and to handle conflict before problems develop. The motivational health checkup model appeared to encourage a broad range of couples who might not have otherwise sought relationship services to deliberately take care of their marital health [29]. A study chooses 54 married subjects who were treated with exposure and response prevention for severe Obsessive Compulsive Disorder. Almost $50 \%$ of the subjects were maritally distressed prior to treatment. Marital distress was significantly reduced following the three-week course of behavior therapy for subjects who were distressed initially. $42 \%$ of the individuals who were maritally distressed prior to treatment were no longer distressed following treatment. All subjects reported a reduction in their level of demandingness and dependency on their spouses. In addition, the maritally distressed subjects reported fewer arguments with their partners following treatment [15]. There are associations between interpersonal cognitive complexity and three marital communication skills: communication effectiveness, predictive accuracy, and perceptual accuracy. Cognitive complexity was moderately associated with perceptual accuracy, weakly associated with communication effectiveness, and not associated with predictive accuracy [30].

Problems in a post hoc selection of patients and measures are compounded by multivariate analyses inappropriate to the sample size, over fitted regression equations, and graphic displays of results with truncated axes that easily are misinterpreted as depicting dramatic differences where there are only marginally different and clinically insignificant effects. Given previous claims of a robust treatment effect, the question is begged whether marital distress moderates any effects of intervention. Unfortunately, examination of such an interaction is precluded by the small size of the convenience sample. Authors should exercise restraint in interpreting post hoc analyses of clinical trials, particularly when vulnerable patients may be listening [31]. This systematic review shows that marital distress can be prevented efficiently. In order to promote their health, spouses with disease should be eager to do something, such as keeping good relationships with each other.

\section{CONCLUSIONS}

1) Spouses with disease have greater psychological and marital distress than spouses without disease. These results highlight the importance of interpersonal perceptions in intimate relationships and provide preliminary groundwork for future research on cognitions in spouses with disease. The study reviews the effect of marital distress on the progression of the disease over time. An understanding of the impact of marital distress on disease progression has major implications. Although the number of articles examining the link between marital distress and disease progression is limited, there are notable strengths to this small body of research and consistent findings of detriment to disease progression among spouses who are involved in marital distress. Recom- 
mendations for the issue are presented. The more a person knows about his disease, the better he is able to design coping strategies for living with a progressive disease. And good communication between spouses may be a useful means to solve psychological problems.

2) Our study has important limitations. First, we only included studies published in the English language. The rationale for this decision is that our research plan is to first identify or adapt a symptom screening tool for use in English with later translation into other languages. Second, it is possible that there are symptom screening tools being used in practice that have not been evaluated in the peer-reviewed literature. Another limitation of our study is the inclusion of scales which address spousal disease alone. A final limitation is that our review excludes single symptom scales. Although these scales are extremely important in clinical practice and research, they do not address our goal to identify a scale which could be potentially used as a symptom screening instrument or adapted for this purpose. Another potential shortcoming could be that we included studies also from the spousal population. Such studies could have biased study samples either through a healthy spousal effect or the opposite, in the case of physically undemanding jobs. In our case, a healthy spousal effect would probably not be pronounced, as we on purpose did not include spousal populations representing marital distress. Also, there were no obvious differences in outcomes between studies of the general and spousal populations.

3) This review has looked at the prevalence of a series of marital distress in the spousal populations and will serve not only as a reference for future studies, but also as a guide for clinicians in general. Firstly, a larger population of spousal patients must be expected in the future and thus calls for more attention on developing optimal spousal patient management protocols. Secondly, it is important for a person to maintain a sufficient public health in order to maintain an active life in the marriage. In other words, political programmes as well as primary and secondary health care programmes accommodated to the future needs are necessary in order to maintain (or ideally improve) the quality of life in the spousal population.

\section{ACKNOWLEDGEMENTS}

This research was supported by general support from planning program from education department of Henan province in China: study on quality of life of left-behind elderly in poor areas (2013-GH-287).

\section{AUTHORS' CONTRIBUTIONS}

Both authors helped to plan the review. MG and BXH performed the literature review. $\mathrm{MG}$ and $\mathrm{BXH}$ interpreted the findings. MG wrote the first draft. Both au- thors participated in completing the manuscript. Both authors read and approved the final manuscript.

\section{REFERENCES}

[1] Jackman-Cram, S., Dobson, K.S. and Martin, R. (2006) Marital problem-solving behavior in depression and marital distress. Journal of Abnormal Psychology, 115, 380384. http://dx.doi.org/10.1037/0021-843X.115.2.380

[2] Carels, R.A., Szczepanski, R., Blumenthal, J.A. and Sherwood, A. (1998) Blood pressure reactivity and marital distress in employed women. Psychosomatic Medicine, 60, 639-643.

[3] Sandberg, J.G., Yorgason, J.B., Miller, R.B. and Hill, E.J. (2012) Family-to-work spillover in Singapore: Marital distress, physical and mental health, and work satisfaction. Family Relations, 61, 1-15. http://dx.doi.org/10.1111/j.1741-3729.2011.00682.x

[4] Mead, D.E. (2002) Marital distress, co-occurring depression, and marital therapy: A review. Journal of Marital and Family Therapy, 28, 299-314. http://dx.doi.org/10.1111/j.1752-0606.2002.tb01188.x

[5] Ahern, D.K., Follick, M.J. and Adams, A.E. (1984) Emotional and marital distress in spouses of chronic low back pain patients. Pain, 18, S15. http://dx.doi.org/10.1016/0304-3959(84)90154-4

[6] Zhou, E.S., Kim, Y., Rasheed, M., Benedict, C., Bustillo, N.E., Soloway, M., Kava, B.R. and Penedo, F.J. (2011) Marital satisfaction of advanced prostate cancer survivors and their spousal caregivers: The dyadic effects of physical and mental health. Psycho-Oncology, 20, 1353-1357. http://dx.doi.org/10.1002/pon.1855

[7] Wang, K.Y., Wang, K.H. and Zhang, Z.P. (2011) Healthrelated quality of life and marital quality of vitiligo patients in China. Journal of the European Academy of Dermatology and Venereology, 25, 429-435. http://dx.doi.org/10.1111/j.1468-3083.2010.03808.x

[8] Renshaw, K.D., Rodebaugh, T. L. and Rodrigues, C.S. (2010) Psychological and marital distress in spouses of Vietnam veterans: Importance of spouses' perceptions. Journal of Anxiety Disorders, 24, 743-750. http://dx.doi.org/10.1016/j.janxdis.2010.05.007

[9] Kelly, A.B., Halford, W.K. and Young, R.M. (2000) Maritally distressed women with alcohol problems: The impact of a short-term alcohol-focused intervention on drinking behaviour and marital satisfaction. Addiction, 95, 1537-1549. http://dx.doi.org/10.1046/j.1360-0443.2000.951015378.x

[10] Yang, H.C. and Schuler, T.A. (2009) Marital quality and survivorship: Slowed recovery for breast cancer patients in distressed relationships: Marital Distress and the Health of Breast Cancer Patients. Cancer, 115, 217-228. http://dx.doi.org/10.1002/cncr.23964

[11] Wittenberg, L., Yutsis, M., Taylor, S., Davis, J.G., Isberg, C.B., Star, P. and Spiegel, D. (2010) Marital status predicts change in distress and well-being in women newly diagnosed with breast cancer and their peer counselors. The Breast Journal, 16, 481-489. 
http://dx.doi.org/10.1111/j.1524-4741.2010.00964.x

[12] Whisman, M.A. (2007) Marital distress and DSM-IV psychiatric disorders in a population-based national survey. Journal of Abnormal Psychology, 116, 638-643. http://dx.doi.org/10.1037/0021-843X.116.3.638

[13] Whisman, M.A. and Schonbrun, Y.C. (2009) Social consequences of borderline personality disorder symptoms in a population-based survey: Marital distress, marital violence, and marital disruption. Journal of Personality Disorders, 23, 410-415.

http://dx.doi.org/10.1521/pedi.2009.23.4.410

[14] Whisman, M.A., Uebelacker, L.A. and Settles, T.D. (2010) Marital distress and the metabolic syndrome: Linking social functioning with physical health. Journal of Family Psychology, 24, 367-370. http://dx.doi.org/10.1037/a0019547

[15] Riggs, D.S., Hiss, H. and Foa, E.B. (1992) Marital distress and the treatment of Obsessive Compulsive Disorder. Behavior Therapy, 23, 585-597. http://dx.doi.org/10.1016/S0005-7894(05)80223-0

[16] Satin, J.R., Linden, W. and Philips, M.J. (2009) Depression as a predictor of disease progression and mortality in cancer patients: A metaanalysis. Cancer, 115, 5349-5361. http://dx.doi.org/10.1002/cncr.24561

[17] Hahlweg, K. and Richter, D. (2010) Prevention of marital instability and distress. Results of an 11-year longitudinal follow-up study. Behaviour Research and Therapy, 48, 377-383. http://dx.doi.org/10.1016/j.brat.2009.12.010

[18] Frank, E., Anderson, C. and Rubinstein, D. (1980) Marital role ideals and perception of marital role behavior in distressed and non distressed couples. Journal of Marital and Family Therapy, 6, 55-63.

http://dx.doi.org/10.1111/j.1752-0606.1980.tb01705.x

[19] Levin, J.B., Sher, T.G. and Theodos, V. (1997) The effect of intracouple coping concordance on psychological and marital distress in infertility patients. Journal of Clinical Psychology in Medical Settings, 4, 361-372. http://dx.doi.org/10.1023/A:1026249317635

[20] Schonbrun, Y.C. and Whisman, M.A. (2010) Marital distress and mental health care service utilization. Journal of Consulting and Clinical Psychology, 78, 732-736. http://dx.doi.org/10.1037/a0019711

[21] Kung, W.W. (2000) The intertwined relationship between depression and marital distress: Elements of marital therapy conducive to effective treatment outcome. Journal of Marital and Family Therapy, 26, 51-63. http://dx.doi.org/10.1111/j.1752-0606.2000.tb00276.x

[22] Carels, R.A., Sherwood, A., Szczepanski, R. and Blumen- thal, J.A. (2000) Ambulatory blood pressure and marital distress in employed women. Behavioral Medicine, 26, 80-85. http://dx.doi.org/10.1080/08964280009595755

[23] Halford, W.K., Bouma, R., Kelly, A. and McD Young, R. (1999) Individual psychopathology and marital distress. Analyzing the association and implications for therapy. Behavior Modification, 23, 179-216. http://dx.doi.org/10.1177/0145445599232001

[24] Hjemboe, S. and Butcher, J.N. (1991) Couples in marital distress: A study of personality factors as measured by the MMPI-2. Journal of Personality Assessment, 57, 216-237. http://dx.doi.org/10.1207/s15327752jpa5702_3

[25] Hahlweg, K., Revenstorf, D. and Schindler, L. (1982) Treatment of marital distress: Comparing formats and modalities. Advances in Behaviour Research and Therapy, 4, 57-74. http://dx.doi.org/10.1016/0146-6402(82)90005-4

[26] Baucom, D.H., Shoham, V., Mueser, K.T., Daiuto, A.D. and Stickle, T.R. (1998) Empirically supported couple and family interventions for marital distress and adult mental health problems. Journal of Consulting and Clinical Psychology, 66, 53-88. http://dx.doi.org/10.1037/0022-006X.66.1.53

[27] Pihet, S., Bodenmann, G., Cina, A., Widmer, K. and Shantinath, S. (2007) Can prevention of marital distress improve well-being? A 1 year longitudinal study. Clinical Psychology \& Psychotherapy, 14, 79-88. http://dx.doi.org/10.1002/cpp.522

[28] Markman, H.J. and Hahlweg, K. (1993) The prediction and prevention of marital distress: An international perspective. Clinical Psychology Review, 13, 29-43. http://dx.doi.org/10.1016/0272-7358(93)90006-8

[29] Morrill, M.I., Eubanks-Fleming, C., Harp, A.G., Sollenberger, J.W., Darling, E.V. and Cördova, J.V. (2011) The marriage checkup: Increasing access to marital health care. Family Process, 50, 471-485. http://dx.doi.org/10.1111/j.1545-5300.2011.01372.x

[30] Denton, W.H., Burleson, B.R. and Sprenkle, D.H. (1995) Association of interpersonal cognitive complexity with communication skill in marriage: Moderating effects of marital distress. Family Process, 34, 101-111. http://dx.doi.org/10.1111/j.1545-5300.1995.00101.x

[31] Coyne, J.C. (2010) Marital quality and survivorship: Slowed recovery for breast cancer patients in distressed relationships: Marital distress and the health of breast cancer patients. Cancer, 116, 1009. http://dx.doi.org/10.1002/cncr.24804 